\title{
Using e-book annotations to develop deep reading
}

\author{
$\operatorname{Mark}$ Jensen $^{1}$ and Lauren Scharff ${ }^{2}$
}

\section{Framework}

In the course of conducting two SoTL studies on the benefits and challenges of using ebooks in place of paper books we have refined and are sharing a handful of best practices to enhance the development of critical reading. Critical reading has been the focus of a great deal of research (Collins, Brown \& Holum, 1991; Handsfield \& Jimenez, 2011), and some of this research has focused on the ways that annotation practices enhance critical reading skills (Hoff, Wehling \& Rothkugel, 2009; Zywica \& Gomez, 2008). Our approach is distinctive insofar as we combine apprenticeship and comprehension strategies immersed in the e-text environment as part of a semester-long effort at the collegiate level.

Critical readers of primary texts have typical foundational goals: they aim to discover an author's central message, thesis, or narrative. But critical readers also want more. For example, they pay attention to the genre of the text and what might be known about the author's context. They aim to make sense of the author's support, defense, and development of the central message. They also challenge the text, raising questions and objections not only about the truth of the central message, but also about the author's argument in its defense. In the end, they see each text as part of a conversation in which their own reflections become new contributions to advance our collective understanding of the issues in question.

Although we can explain what behaviors we expect of critical readers, the practice of critical reading is challenging to cultivate (Conley \& Wise, 2011). The practice itself is typically carried out privately and individually. Critical readers outline, extract arguments, mark critical passages and important claims, and write out notes alongside the text that include their own observations, questions, objections, and commentary. To be sure: teachers can present the results of exemplary critical reading, but our challenge is to find a way to model the practice of critical reading and to design courses that provide opportunities for students to develop as apprentices in this practice (Collins, et al., 1991).

Paper textbooks present obvious challenges to modeling and apprenticeship due to the relative permanence of annotations on paper, the lack of space to make more than short notes, and the difficulty for instructors to access and provide feedback on the quality of the annotations. Prior marks and notes in used textbooks are especially challenging as they may distract or shortchange readers when they attempt to make connections on their own. When books are in good condition, many students are loath to mark them up for fear of reducing resale value.

E-texts and e-readers offer tools that overcome the challenges posed by paper textbooks (Anderson-Inman \& Horney, 2007). In an e-text, students can insert (and delete or change) highlights and annotations and they won't ever run out of room to elaborate their thoughts. More importantly, with some thoughtful course design, teachers using e-texts in the classroom can publicly model the art of critical reading while students can work as true apprentices, receiving feedback as they work in class or through the easy electronic sharing of annotations. In our

\footnotetext{
${ }^{1}$ Associate Professor of Philosophy, United States Air Force Academy, mark.jensen@usafa.edu

${ }^{2}$ Director, Program for the Scholarship of Teaching and Learning, United States Air Force Academy, lauren.scharff@usafa.edu
} 
view, the fact that e-texts can make the previously private act of critical reading into a public act represents one of the most positive transformational aspects of these new technologies.

\section{Making it Work}

The courses that we've investigated are small, upper-level reading-intensive courses in Philosophy, but the practices we suggest could be adapted for courses of any size with required reading. We set aside time in an early lesson to train students how to annotate using the tools available within our e-reader platform (Kindle app for the PC). We now incorporate intensive initial training because we learned that a short overview of annotation approaches and software features was not sufficient to make students likely to use the annotation tools of the e-reader. We begin with a bare text passage projected onto a screen at the front of the classroom. Our students have this same text on their laptops in an identical software environment. We then walk through four specific annotation practices associated with critical reading: outlining, connecting, questioning, and objecting to a text.

1. Outlining. The objective of an outline is to reveal the structure of the text, which is more challenging in primary texts due to the lack of headings and detailed tables of contents. We train students how to recognize and make note of signposts, especially key words such as, "first," "next," "therefore," and "moreover."

2. Connecting. Connections to other persons, texts, and objects help identify the author's context. Understanding the context is an important part of understanding the text itself as well as the larger conversation in which that text is but one part. We train students to note these connections.

3. Questioning. Every text requires interpretation. Readers do not share the mind of the author and texts are imperfect media for communication. We train our students to make note of issues that they don't understand or pique their curiosity.

4. Objecting. Texts contain assumptions, claims, practices, principles, etc., that are open to challenge. We train our critical readers to raise objections to their texts as they read.

While it's a good rule of thumb for readers to understand a text before they raise objections to it, we are not suggesting that these practices should be taught sequentially or that, in reading a text, readers should always follow the order above. Different texts will elicit different responses from readers and different readers will approach the same text differently. In other words, these four practices will increase a reader's critical engagement with a text but the specific nature of their employment will depend on the text and the reader.

We therefore introduce all of these practices in a single session, demonstrating how these practices might be undertaken in the e-book app and providing students with a chance to practice on their own machines. At present, electronic tools for most e-book platforms permit students to highlight, bookmark, and comment on an e-text. While highlighting alone can be useful, our focus is training students to use the commenting feature to accomplish the four annotation tasks described above. Outlining can be accomplished by using a numbering system in the running comments, perhaps with titles bolded to distinguish them from connections, questions, and objections. These latter elements can be indicated in a variety of ways; for example, one can begin each of these with a distinct symbol, e.g., "Q:" for question. While students are allowed to create personalized systems of annotation, they are told that any system should distinguish these four different types of critical engagement. 
Our tutorial is only the beginning of the development process. Throughout the semester, we make use of several techniques to reinforce and refine the critical reading practices. The existence of multiple opportunities to practice a skill is foundational to skill development. Further, several of these techniques incorporate some form of feedback, which is also a crucial component of developing a skill (Svinicki, 2004).

The first technique is used when discussing passages in the text as a class at large. The instructor projects the text with his annotations visible for students to compare with the annotations that they've done on the same passage. During discussion, both the instructor and the students share the connections, questions, and objections that they've marked in the text. In this way, there is both public modeling of the instructor annotations as well as engagement and feedback about his and the students' annotations. Our second technique involves an in-class reading workshop in which students work together in small groups to make sense of the author's line of reasoning. They must work together from the text, pointing to the specific passages that animate their connections, questions, and objections. Third, as part of their daily work for the course, students select from their annotations what they regard to be their most significant connection, question or objection and submit this to the instructor before class begins. This assignment holds them accountable for critical reading and also provides support for class discussion. Finally, we require students to turn in a portfolio that contains all of their annotations for each e-text that we assign during the term. While not graded, collection of these portfolios reinforces the value the course places on annotations, and they provide samples of student performance and development so that we can continue to adjust our methods to better cultivate student mastery.

\section{Future Implications}

It is our view that e-texts, especially in the collegiate setting, will eventually become the dominant media form (Simon \& Will, 2013). Although we have some colleagues who show trepidation about allowing students to work on computers during class (Young, 2006), we believe that we should embrace possibilities for enhanced learning with e-texts, especially when it comes to critical reading. The approaches we outline above incorporate modeling and multiple opportunities for practice and feedback, all of which are known to support skill development (Svinicki, 2004). The increased access to and sharing of annotations is central to the benefit of the e-text environment, as these are especially difficult to acquire from students using paper texts, and thus, limit the important aspect of feedback.

Although our courses were face-to-face, many aspects of our approaches can be incorporated into online courses and across a variety of e-reader platforms. We also believe that in the near future, e-text annotation and sharing features will further improve; we have already experienced enhancements in the two years we have used e-texts. Finally, we believe that electronic portfolios including annotations will support assessment of important outcomes such as critical thinking, which will in turn support aspects of the accreditation process.

\section{Acknowledgement}

The views expressed in this article are those of the authors and do not necessarily reflect the official policy or position of the US Air Force, the US Department of Defense, or the US government. 


\section{References}

Anderson-Inman, L., \& Horney, M. (2007). Supported eText: Assistive technology through text transformations. Reading Research Quarterly, 42(1), 153-160. doi: 10.1598/RRQ.42.1.8

Collins, A., Brown, J. \& Holum, A. (1991). Cognitive apprenticeship: Making thinking visible. American Educator: The Professional Journal of the American Federation of Teachers, 15(3), 6$11,38-46$.

Conley, M. \& Wise, A. (2011). Comprehension for what? Preparing students for their meaningful future. Theory Into Practice, 50, 93-99. doi: 10.1080/00405841.2011.558411

Handsfield, L., \& Jimenez, R. (2011). This issue. Theory Into Practice, 50, 81-84. doi: $10.1080 / 00405841.2011 .558409$

Hoff, C., Wehling, U. \& Rothkugel, S. (2009). From paper-and-pen annotations to artifact-based mobile learning. Journal of Computer Assisted Learning, 25, 219-237. doi 10.1111/j.13652729.2008.00297.x

Simon, S., \& Will, M. Textbook publishers revamp e-books to fight used market. Reuters, July 23, 2013. http://www.reuters.com/article/2013/07/23/us-usa-education-textbookidUSBRE96M04520130723. Accessed June 17, 2014.

Svinicki, M. (2004). Learning and Motivation in the Postsecondary Classroom. Bolton, MA, Anker Publishing Co, Inc.

Young, J. (2006). The fight for classroom attention: Professor vs. laptop. Chronicle of Higher Education, 52(39), A27.

Zywica, J. \& Gomez, K. (2008). Annotating to support learning in the content areas: Teaching and learning science. Journal of Adolescent and Adult Literacy, 52(2), 155-164. doi:

10.1598/JAAL.52.2.6 